\title{
EDUCAÇÃO AMBIENTAL E ÁGUA: OS DIFERENTES OLHARES E PERSPECTIVAS DENTRO DA GESTÃO PÚBLICA
}

\author{
Jessica Prudencio Trujillo Souza $^{1}$ e Carolina Messora Bagnolo ${ }^{2}$
}

\begin{abstract}
RESUMO
Atualmente vivemos um cenário de crise ambiental, tendo destaque o elemento água. O diálogo sobre seus diversos usos é realizado por meio dos Comitês de Bacias Hidrográficas $(\mathrm{CBH})$ no qual se insere o $\mathrm{CBH}$ dos rios Piracicaba, Capivari e Jundiaí (Comitês PCJ). Nesse contexto, existe a Câmara Técnica de Educação Ambiental (CT-EA) que discute questões socioambientais relacionadas à água. Sendo assim, a questão orientadora deste artigo é: quais concepções de EA são abordadas na CT-EA no âmbito dos Comitês PCJ? Para elucidar essa questão analisamos documentos, reuniões e entrevistas da CT-EA. Nossos resultados apontam para diversas concepções de EA presentes na CT-EA dos Comitês PCJ, demonstrando esse espaço público é formado por pessoas com diversos olhares, vivências e expectativas sobre o campo da EA.

Palavras-chave: Educação Ambiental, Comitê de Bacias Hidrográficas, Gestão pública, Água.
\end{abstract}

\begin{abstract}
Currently, we live a environmental crisis highlighting the water element. The discussions about the water use is realized from Watersheds Technical Chambers (WTC) including the Piracicaba, Capivari and Jundiaí Rivers WTC (PCJ). In this context, exist the Environmental Education Technical Chamber (EE-TC) that discuss water related socioenvironmental issues. Thus, the guiding question of this paper is: What are the EE conceptions that are addressed in PCJ WTC? For answer this question we analysed documents, meetings and interviews. Our findings showed different EE conceptions in PCJ WTC demonstrating that public space is shaped by people with different views, experiences and expectations on EE.

Keywords: Environmental Education, Watersheds Technical Chambers, Public management, Water.
\end{abstract}

\section{INTRODUÇÃO}

A questão ambiental na sociedade contemporânea advém de variadas situações e contextos como, por exemplo, o potencial nuclear mundial, sendo bélico ou pacífico, técnicas modernas de engenharia genética, os problemas ambientais globais ${ }^{3}$, guerras patrocinadas ou motivadas pela exploração dos "recursos" naturais, as numerosas pessoas que sobrevivem do lixo. Esses diversos problemas socioambientais nos indicam

\footnotetext{
1 Mestra em Ensino de Ciências e Matemática - Universidade Estadual de Campinas.

2 Professora do Colégio Técnico de Limeira - COTIL/Unicamp.

Como exemplo: mudanças climáticas, perda da biodiversidade, danos à camada de ozônio.
} 
que a questão ambiental não é uma questão passageira, não é um fenômeno provisório, mas algo que veio a se instaurar em nossa sociedade. São problemas que envolvem as diversas relações entre a sociedade e o restante da natureza e as relações entre os próprios seres humanos, ocasionando assim uma degradação humana, social e ambiental (LIMA, 2011).

Nesse sentido, em busca de relações sustentáveis entre os seres humanos e destes com o restante da natureza, a educação foi reconhecida como tendo um papel importante para a mudança das mentalidades em relação à problemática ambiental, ao lado de outras iniciativas políticas, jurídicas, institucionais, econômicas e tecnológicas, segundo os primeiros analistas da crise ambiental contemporânea (LIMA, 2011).

A partir do reconhecimento do potencial da educação como elemento relevante no enfrentamento da crise ambiental, surgiram as primeiras iniciativas de educação ambiental (EA), que se desencadearam como processos sinérgicos, despertando ações esparsas nos movimentos da sociedade civil e nas atividades (em geral espontâneas e pontuais) de educadores(as) e de escolas interessados(as) na problemática e na formulação de respostas para sua superação (LIMA, 2011).

O campo ambiental se dá no encontro das relações entre a sociedade e o restante da natureza tendo como reflexos o surgimento de subcampos sociais e educacionais, entre os quais está presente a EA, mas que também incluem a gestão ambiental, a sociologia ambiental, o direito ambiental, a economia ambiental e tantos outros novos arranjos (LIMA, 2011).

Em meio a esse cenário de crise e emergência da educação como alternativa de mudança social, surgem várias interpretações sobre o que é EA, sendo realizadas inúmeras práticas educativas, com extensa diversidade de conceitos, práticas e metodologias. Essa diversidade, segundo Reigota (2000), é bastante positiva, devido a nossa realidade ambiental ser complexa. Assim, a EA como campo do saber, nasce como um fenômeno complexo e multidimensional, sendo constituída por contribuições de disciplinas e matrizes político-pedagógicas e filosóficas, diversos atores e movimentos sociais (LIMA, 2011). Nesse contexto, a busca por um único conceito da EA no Brasil foi abandonada pela percepção da pluralidade de olhares e atores que a formava. Isso conduziu esforços de diferenciação desses conhecimentos e posicionamentos pedagógicos, políticos e epistemológicos (RINK, 2014). 
No campo da EA, Carvalho (2002), Guimarães (2000), Sauvé (2005), entre outros(as) autores(as), fizeram suas classificações desse campo denominando-as como "corrente", "concepção", "vertente", "tendência" ou "modalidade" em EA, de acordo com suas características pessoais de como enxergam o mundo dentre os diferentes aspectos político, filosófico, pedagógico, ambiental, social, cognitivo, entre outros e a possível interface de alguns desses. Assim sendo, não fica explícito pelos(as) autores(as) quais foram os diversos critérios que os(as) fizeram construir tal(ais) classificação(ões).

A primeira tentativa de classificar o campo da EA na literatura brasileira pode ser creditada à Sorrentino $(1995 ;$ 1997). Ele classificou a EA em concepções: conservacionista, educação ao ar livre, gestão ambiental e economia ecológica.

A concepção Conservacionista ${ }^{4}$ de EA trazida pelo autor, busca a divulgação dos impactos sobre a natureza causados pelos atuais modelos de desenvolvimento, impedindo o contato humano com a flora e fauna, tendo então a preocupação em preservar os elementos da natureza intocados da ação humana. Por sua vez, a Educação ao Ar Livre tem como adeptos os naturalistas, os escoteiros, os grupos de montanhistas, entre outros, tendo como proposta a sensibilização pelo contato com a natureza. Assumem a EA em caminhadas ecológicas ou no turismo ecológico, por exemplo. A concepção Gestão Ambiental desenvolve uma crítica ao sistema capitalista e à sua lógica predatória em defesa dos recursos naturais e da participação democrática da sociedade civil na resolução dos problemas socioambientais que vivencia. Por fim, na concepção Economia Ecológica, estão presentes o conceito de desenvolvimento sustentável e sociedades sustentáveis (SORRENTINO, 1997).

Reconhecendo a diversidade de abordagens da questão ambiental, Brügger (1994) delineia duas grandes tendências de EA. A primeira, de caráter crítico, seria pautada pelas ciências humanas e sociais, em que os fatores sócio-históricos se sobressaem sobre os fatores técnicos ou naturais na explicação da problemática ambiental. Essa tendência está bastante restrita ao ensino formal, sobretudo ao ensino superior. A outra, denominada pela autora como Adestramento Ambiental, reforça uma visão limitada do ambiente, em que os problemas ambientais são tratados

\footnotetext{
$4 \quad$ O uso dos termos conservacionista e preservacionista é usado indiscriminadamente pelo autor atribuindo-lhes os mesmos significados.
} 
exclusivamente sob a ótica das dimensões naturais e técnicas, excluindo os fatores sociais e políticos. Bagnolo (2010), fazendo uma análise dessas tendências, traz para a discussão que a segunda tendência apresentada tem prevalecido sobre a primeira devido ao fato de ter ocorrido uma fragmentação dos saberes, empobrecendo o diálogo entre as ciências humanas e as ciências naturais e exatas. A ausência desse diálogo deve ser superada para que possamos dar conta da problemática ambiental, ainda mais num contexto onde o saber instrumental, mecânico e tecnicista tem prevalecido.

No mesmo sentido, Amaral (2006) também se utiliza da classificação de Brügger (1994), Adestramento Ambiental, e declara que essa tendência possui forte teor instrumental sendo desprovida de reflexões críticas nas práticas educativas, individualizando a responsabilidade ambiental, negligenciando os fatores políticos e econômicos que recaem sobre o meio ambiente, realizando uma fragmentação, compartimentação e reducionismo de sua imagem. Além dessa tendência, o autor se refere ainda às tendências desenvolvimento sustentável, ecologismo radical e a tendência crítica.

Na tendência Desenvolvimento Sustentável busca-se o equilíbrio entre ambiente e o desenvolvimento econômico, tendo uma visão antropocêntrica, estando a ciência e a tecnologia a serviço da resolução dos problemas ambientais. O Ecologismo Radical preconiza o retrocesso dos atuais padrões de relação entre ser humano e restante da natureza, com o banimento do capitalismo e suas formas desenfreadas de exploração do mundo natural. Atribui à ciência e às tecnologias responsabilidades pela crise ambiental na qual vivemos e prioriza a ética preservacionista, considerando todos os seres vivos com idêntico valor, inclusive o ser humano (AMARAL, 2006).

A última tendência de EA trazida pelo autor é a Crítica, segundo a qual há uma articulação entre diretrizes programáticas e metodológicas que procuram oferecer uma alternativa às críticas feitas às demais tendências, como o antropocentrismo e o cientificismo exagerados. Nessa tendência, não se considera a EA como algo dissociado da educação em geral. Cabe citar que o autor pontua que suas tendências de EA muitas vezes se misturam na prática ou até mesmo tem caráter contraditório, segundo o critério político-pedagógico (AMARAL, 2006). 
Os autores Layrargues e Lima (2014) classificaram a EA em macrotendências, sendo elas a Macrotendência Conservacionista, a Macrotendência Pragmática e a Macrotendência Crítica.

A Macrotendência Conservacionista ${ }^{5}$ tem ligação com os princípios da ecologia, valorizando a dimensão afetiva do ser humano para com o restante da natureza e na mudança do comportamento individual em relação ao ambiente, com viés antropocêntrico.

É uma tendência conservadora que faz com que as ações no âmbito da educação e da sociedade não questionem a estrutura social posta pelo modelo capitalista predatório, propondo ações em pequena escala e pontuais. Tem sua consolidação histórica com ações que vinculam a EA à "pauta verde", como biodiversidade, unidades de conservação, ecoturismo e experiências agroecológicas, porém apresentando um limitado potencial de contribuir para a transformação social devido ao fato de estar distanciada das dinâmicas sociais e políticas e seus conflitos (LAYRARGUES; LIMA, 2014).Os autores colocam que essa tendência não parece ser hegemônica no campo da EA na primeira década do século XXI, onde a tendência pragmática tem um forte papel.

A Macrotendência Pragmática, que abrange, sobretudo, as correntes da Educação para o Desenvolvimento Sustentável- contextualizadas também por Sorrentino (1995, 1997) e Amaral (2006) - e para o Consumo Sustentável, tem como cunho o ambientalismo de resultados, do pragmatismo contemporâneo e da ecologia de mercado, decorrente da hegemonia neoliberal imposta mundialmente desde a década de 1980 e no contexto brasileiro desde os anos 1990.

Essa tendência tem como fio condutor a dominância da lógica do mercado sobre as outras camadas e setores sociais, a ideologia do consumo como principal objetivo, a preocupação com a produção crescente de resíduos sólidos, a revolução tecnológica como última fronteira do progresso e, nos mecanismos empresariais, a presença da economia e consumo verde, da responsabilidade socioambiental, de certificações e desenvolvimento limpo e ecoeficiência. Dessa forma, essa macrotendência converge com a noção do Consumo Sustentável, relacionando-se também com a economia de

5 Conforme descrito, a Macrotendência Conservacionista se expressa pela concepção conservacionista (SORRENTINO, 1995; 1997), do adestramento ambiental (BRÜGGER, 1994; AMARAL, 2006), pelo autoconhecimento e pelas atividades de senso-percepção ao ar livre (SORRENTINO, 1995; 1997) e, em parte, pelo ecologismo radical (AMARAL, 2006). 
energia ou de água, o mercado de carbono, as tecnologias ecológicas, a diminuição da "pegada ecológica" e demais contextos colocados pelo conservadorismo dinâmico que trabalham mudanças superficiais, tecnológicas e comportamentais (LAYRARGUES; LIMA, 2014).

Tem como característica a ausência de reflexão, que permite a compreensão das causas e consequências dos problemas ambientais. Essa ausência se configura pela crença da neutralidade da ciência, resultando na percepção despolitizada das relações sociais e com o restante da natureza. Outra característica é a busca desenfreada por ações factíveis que tragam resultados vislumbrando um futuro sustentável. Esses elementos reduzem as possibilidades de enfrentamento político da crise (LAYRARGUES; LIMA, 2014).

Importante destacar que os autores colocam que ambas macrotendências (conservacionista e pragmática) representam uma mesma linhagem de pensamento que foi se ajustando conforme as imposições econômicas e políticas do momento atual, neoliberal e pragmático.

Por fim, os autores contextualizam a Macrotendência Crítica $^{6}$, que está imbuída dos elementos que constituem as correntes de Educação Ambiental Popular, Emancipatória, Transformadora e Gestão Ambiental. Sustenta-se da ideia crítica de dominação do ser humano e dos mecanismos de acumulação do Capital, buscando o enfrentamento político das desigualdades e da injustiça socioambiental. Opõem-se às tendências conservadoras, buscando contextualizar e politizar o debate ambiental e problematizar as contradições dos modelos de desenvolvimento e de sociedade (LAYRARGUES; LIMA, 2014).

A EA Crítica tende a alinhar-se com o pensamento da complexidade, percebendo que as questões contemporâneas, como é o caso da questão ambiental, não encontram respostas em soluções reducionistas. Dessa maneira, demonstra potencial para desconstruir as falsas dualidades que o paradigma cartesiano impôs nas relações entre indivíduo e sociedade, sujeito e objeto do conhecimento, saber e poder, natureza e cultura, ética e técnica, entre outras dualidades (LAYRARGUES; LIMA, 2014).

6 A Macrotendência Crítica abarca a concepção de Gestão Ambiental trazida por Sorrentino (1995, 1997) e a tendência Crítica proposta por Brügger (1994), atualizada e ampliada por Amaral (2006), assim como, parcialmente, o ecologismo radical (Amaral, 2006). 
Neste sentido, a modernidade atual, que impõe novos ritmos e tempos, cheia de desafios e incertezas, não permite reducionismos, exigindo-se a abertura, inclusão e diálogo sobre as diversas questões sociais, caracterizando um pensamento crítico.

Atualmente uma das maiores problemáticas ambientais se refere ao elemento natural água e suas diversas utilizações. A água tem uma característica muito específica no contexto social e, considerando as várias dimensões essenciais dela, esta se torna eixo central das relações sociais dentro de uma bacia hidrográfica. Quando ocorre a poluição e a escassez, potencializam-se os conflitos sociais que, de outro modo, já são inerentes às classes sociais, onde as periferias ficam com escassez de água enquanto que os bairros nobres das cidades ficam abastecidos juntamente com o setor industrial e agrícola (PAULA, 2002).

Dessa forma, o gerenciamento da água pelo poder público se faz necessário, tendo o entendimento de que as bacias hidrográficas são unidades físico-territoriais de planejamento e gerenciamento dos recursos hídricos e que seu manejo integrado é fundamental para assegurar que estes recursos sejam utilizados de maneira sustentável (PAULA, 2002). Os recursos hídricos têm diferentes usos e usuários e as ações de alguns podem ter efeito de longo alcance para muitos outros tornando as interdependências e os conflitos inerentes na gestão de bacias hidrográficas (BARBI, 2007).

No Brasil, a gestão da água se dá por meio de Comitês de Bacias Hidrográficas $(\mathrm{CBH})$, que foram inspirados no modelo francês para a gestão dos recursos hídricos, com avanços na questão de participação social, com uma gestão descentralizada e compartilhada (BARBI, 2007).

Os CBH foram criados em níveis estaduais e federal a partir de 1990, sendo constituídos por uma estrutura participativa denominada "tripartite paritária", contando com a presença do Estado, dos Municípios e da Sociedade Civil (PAULA, 2002; BARBI, 2007; ABERS et al, 2009). Essa dinâmica possibilita uma melhor interação entre os diversos atores envolvidos, porém existe a dificuldade de esses diversos atores apresentarem visões divergentes sobre o processo e os objetivos de gestão e isso pode dificultar a busca de soluções mais benéficas para o coletivo (BARBI, 2007).

Poucos estudos têm se debruçado sobre a motivação da descentralização da gestão da água no Brasil, que faz com que os atores sociais, em níveis locais, aceitem 
maiores responsabilidades. Alguns examinam as causas da descentralização como resultado de barganhas políticas onde diferentes atores sociais buscam acesso a recursos financeiros (ABERS; JORGE, 2005).

Embora não esteja muito claro as razões da descentralização da gestão das águas, o fato é que isso possibilita a participação da sociedade na gestão, apontando para uma ação democrática.

No ano de 1993 ocorreu a criação dos Comitês de Bacia Hidrográfica dos rios Piracicaba, Capivari e Jundiaí (CBH-PCJ, Comitês PCJ) que compreendem municípios do estado de São Paulo e Minas Gerais. Esse Comitê é considerado o primeiro instituído no Estado de São Paulo. Esse fórum de discussão tornou-se um espaço de fundamental importância para a promoção de discussões de assuntos relacionados aos recursos hídricos nas bacias PCJ (LAHÓZ, 2006).

Nesse sentido de criação dos Comitês PCJ, houve uma certa convergência política entre prefeitos de municípios das três bacias: Piracicaba, Capivari e Jundiaí. Dessa forma, ocorreu sua criação como forma de gestão e acordos políticos de interesse. Pensando geologicamente e no espaço geográfico, o conceito de bacia hidrográfica não se enquadra aos Comitês PCJ, pois eles são compostos por três bacias e sete sub-bacias principais.

Os Comitês PCJ aprovaram, no ano de 2003, normas gerais para criação e funcionamento de Câmaras Técnicas (CT) que são equipes colegiadas, com característica consultiva, que tratam sobre diversos temas da bacia como saneamento, reflorestamento, entre outros. Dessa forma, a Câmara Técnica de Educação Ambiental (CT-EA) dos Comitês PCJ foi criada oficialmente no ano de 2003 por meio da Deliberação Conjunta dos Comitês PCJ nº02/03, de 22/05/2003, apesar de os Comitês PCJ terem ações de EA anteriores a esse período.

\section{PROCEDIMENTOS METODOLÓGICOS}

Esse artigo é a síntese de uma pesquisa de dissertação ${ }^{7}$, no qual foi realizado um estudo de caso tendo como objeto de estudo a CT-EA dos Comitês PCJ. Nesse contexto,

\footnotetext{
7 Pesquisa de dissertação da primeira autora desse artigo intitulada "Comitês de Bacias Hidrográficas dos rios Piracicaba, Capivari e Jundiaí: uma análise da Câmara Técnica de Educação Ambiental", desenvolvida no Programa de Pós-Graduação em Ensino de Ciências e Matemática na Universidade Estadual de Campinas, defendida no ano de 2016.
} 
essa pesquisa apresentou a seguinte questão orientadora: Quais concepções de Educação Ambiental são abordadas na Câmara Técnica de Educação Ambiental no âmbito dos Comitês PCJ?

Assim, no que se refere à CT-EA, buscamos alcançar os seguintes objetivos: i) identificar e discutir as concepções de EA presentes nos documentos orientadores, nas reuniões e oficinas da CT-EA, bem como nos discursos de duas gestoras manifestadas em entrevistas; ii) analisar a coerência e/ou incoerência das concepções de EA entre os documentos orientadores; iii) analisar a coerência e/ou incoerência das concepções de EA entre as práticas $^{8}$ desenvolvidas; iv) analisar a coerência e/ou incoerência das concepções de EA entre as entrevistas. Por fim, nós objetivamos realizar uma análise comparativa entre os documentos, as práticas e entrevistas.

\section{Elementos e Etapas da Pesquisa}

As fontes de dados e os respectivos instrumentos foram constituídos pelos Documentos Orientadores (disponíveis em www.comitespcj.com.br) tais como a Deliberação de Criação da CT-EA dos Comitês PCJ, as Políticas de EA dos Comitês PCJ, o Programa de EA dos Comitês PCJ e, a Deliberação que trata sobre as diretrizes para programas de EA a serem apresentados no âmbito do licenciamento ambiental; pelas Entrevistas Semi-estruturadas com a Coordenadora e Coordenadora Adjunta da CT-EA, mandato 2013-2015, realizadas com o auxílio de gravador e transcrições $a$ posteriori; e, pelas Atas e Observações das Reuniões e Oficinas da CT-EA, com anotações em diário de campo.

As fases de investigação aconteceram de três maneiras: $1^{\text {a }}$ Fase - Análise dos Documentos da CT-EA dos Comitês PCJ; $2^{\mathrm{a}}$ Fase - Pesquisa de Campo; e $3^{\mathrm{a}}$ Fase Análise dos Dados obtidos ${ }^{9}$.

- $1^{a}$ Fase - Análise dos Documentos Orientadores da Câmara Técnica de Educação Ambiental dos Comitês PCJ

Foram analisados os documentos orientadores da CT-EA dos Comitês PCJ com relação à(s) concepção(ões)de EA ali presente(s). A pesquisa documental levou em

\footnotetext{
8 O termo "práticas" refere-se às reuniões e oficinas (atas e observações) e entrevistas.

$\mathrm{O}$ corpus documental analisado pode ser obtido na íntegra acessando a Biblioteca Digital da Universidade Estadual de Campinas, disponível no endereço eletrônico <http://www.bibliotecadigital.unicamp.br/document/list.php?tid=7>.
} 
consideração documentos de fontes primárias (uso de documentos de arquivos públicos), conforme descrição de Marconi e Lakatos (2011).

- $2^{a}$ Fase - Pesquisa de Campo

Os dados de campo da CT-EA foram coletados a partir de entrevistas com representantes da CT-EA dos Comitês PCJ (Coordenadora e Coordenadora Adjunta), com o uso de roteiros semi-estruturados, gravação de áudio e transcrição. As entrevistas aconteceram em fevereiro de 2014 com a coordenadora e em fevereiro de 2015 com a coordenadora adjunta. $\mathrm{O}$ uso de roteiro semi-estruturado permitiu liberdade à pesquisadora para adaptar as perguntas a determinadas situações da entrevista ou alterar a ordem dos tópicos pré-definidos.

Segundo Freire (1992), a entrevista proposta pelo diálogo busca uma condição de horizontalidade e igualdade na relação. Além disso, conforme Szymanski et al. (2004), a entrevista face a face é uma situação de interação humana em que estão em jogo percepções, expectativas, sentimentos, preconceitos e interpretações do entrevistador e entrevistado.

As análises das entrevistas semi-estruturadas por meio das transcrições das mesmas foram realizadas com base em Szymanski et al. (2008), levando em consideração o contato inicial da entrevistadora com as entrevistadas, a condução das entrevistas, a transcrição das entrevistas e sua pré-análise realizada pelas entrevistadas.

Outros dados de campo foram as observações das reuniões e oficinas da CT-EA, com a elaboração de um diário de campo, bem como a leitura e análise das atas das reuniões observadas. Foram observadas 6 reuniões ordinárias, 2extraordinárias e 2 oficinas, entre os meses de fevereiro do ano de 2014 e junho do ano de 2015. Segundo Marconi e Lakatos (2011), a pesquisa de campo é utilizada com o objetivo de conseguir informações ou conhecimentos sobre um problema para o qual se busca uma resposta, ou comprovação de uma hipótese, ou, ainda, descobrir novos fenômenos ou as relações entre eles.

\section{- $3^{a}$ Fase - Análise de Dados}

Para analisar os documentos, reuniões e entrevistas, perante as concepções de EA, nós utilizamos como referencial teórico as Macrotendências de EA descritas por Layrargues e Lima (2014) (detalhadas na introdução desse artigo). A escolha desse referencial teórico tem como embasamento e alinhamento o viés político-pedagógico 
presente na classificação por eles apresentadas, sendo que os autores abarcam em suas vertentes ideias de outros(as) autores(as).

Os dados obtidos foram analisados segundo duas categorias propostas por nós: i) Concepção ${ }^{10}$ de EA e ii) Coerência/Incoerência da(s) concepção(ões) de EA reveladas. Para auxiliar a classificação os dados obtidos nas categorias propostas, nós construímos três indicadores de análise, 1) Perspectiva de Ambiente: ecológica, utilitarista e/ou multidimensional; 2) Nível de Participação dos Membros da CT-EA: horizontal colaborativa e/ou verticalizada; e 3) Transformação da Realidade: política, multidimensional, ecológica e/ou informativa.

\section{1) Perspectiva de Ambiente: ecológica, utilitarista elou multidimensional:}

Segundo Layrargues e Lima (2014), a perspectiva ecológica de ambiente tem como base a ciência ecológica priorizando a conservação e a preservação da natureza. No campo da EA, esse pensamento indica uma EA Conservadora, quando não assume um posicionamento ecologista radical.

A perspectiva utilitarista de ambiente, por sua vez, considera a natureza como recurso ambiental, preocupando-se com questões de produção e de consumo, acompanhadas ou não por preocupações de sustentabilidade, sinalizando uma concepção Pragmática de EA.

Por fim, a perspectiva multidimensional de ambiente traz um olhar amplo considerando não só a natureza, mas as dimensões sociais, culturais e políticas também. Nesse sentido, essa perspectiva aponta para uma EA Crítica.

2) Nível de Participação dos Membros da CT-EA: horizontal colaborativa elou verticalizada:

No sentido de participação horizontal colaborativa, entendo como uma participação efetiva acontecendo de forma pró-ativa, onde o ator social participa das discussões durante as reuniões, envolve-se em grupos de trabalho, em oficinas, na elaboração e colaboração de deliberações, documentos e outras ações da CT-EA.

\footnotetext{
10 Para efeito do texto, utilizarei o termo concepção, perspectiva e viés como tendo os mesmos sentidos e significados.
} 
Com relação à participação verticalizada, entendemos como uma participação hierárquica entre os membros ou até mesmo de forma impositiva e autoritária durante as reuniões. Esta forma impositiva se manifesta no aumento do tom da voz em discussões, expressões orais imperativas, entre outras manifestações.

3) Transformação da Realidade: política, multidimensional, ecológica elou informativa:

Entendemos a transformação da realidade política quando a CT-EA propõe mudanças ou formulação de novas políticas públicas em que o campo da EA seja incluído.

O viés multidimensional visa mudanças na sociedade em geral, por meio de intervenções políticas, culturais, econômicas, educacionais, sociais, com posturas reflexivas e críticas.

A transformação de realidade sob o viés ecológico prevê ações acríticas e pontuais visando melhorias no meio ambiente "ecológico" tendo cunho conservacionista, tendo como exemplos ações como plantio de mudas, despoluição de rios, obras de saneamento, contemplação da natureza, entre outros.

Por fim, a transformação de realidade numa perspectiva informativa, quando as ações são pontuais e se pautam em questões de produção e distribuição de materiais e campanhas "educativas" de cunho informativo, como exemplo: semana da água, semana do meio ambiente, entre outros.

Após essa etapa de análise, verificamos a coerência/incoerência da(s) concepção(ões) de EA presentes, realizando o cruzamento de dados a partir das análises: entre os documentos orientadores; entre as reuniões; entre as entrevistas. Em um segundo momento, realizamos a análise comparando as entrevistas com as reuniões e com os documentos, realizando uma triangulação de fontes de dados, segundo AlvesMazotti e Gewandsznajder (2001).

\section{RESULTADOS E DISCUSSÃO}

Concepções de Educação Ambiental 
A partir das Análises dos Documentos, no sentido de desvelar as concepções de EA presentes na CT-EA, iniciarmos essas análises pelo documento de aprovação de criação da CT-EA dos Comitês PCJ. Esse documento propõe uma EA como ferramenta e não como processo, corroborando com a macrotendência pragmática de Layrargues e Lima (2014) em que é preconizado o ambientalismo de resultados.

Das análises das Políticas de EA dos Comitês PCJ(Primeira Política de $E A^{11} \mathrm{e}$ Política Atual de $E A^{12}$ ), conseguimos depreender da uma concepção Crítica de EA. Como princípios da EA nos Comitês PCJ, de maneira geral, a perspectiva de ambiente tem aspecto multidimensional, em que se reconhece o ambiente como sendo interdependente entre diversos fatores e aspectos que o compõe e reconhece questões socioambientais valorizando os saberes locais. Como nível de participação, os documentos apontam para a construção coletiva e contínua de conhecimentos, articulação entre as demais CT dos Comitês PCJ e a produção coletiva de materiais educomunicativos, sendo essa produção caracterizada como transformação da realidade juntamente com a proposta de construir a cidadania por meio da participação em espaços de tomada de decisão. Esse olhar nos mostra uma concepção de EA Crítica, corroborando com o referencial teórico Layrargues e Lima (2014).

Contrastando com essa perspectiva, o documento que versa sobre o Programa de EA dos Comitês PCJ demonstra, no geral, uma visão de EA Pragmática visando à resolução dos problemas ambientais buscando a melhoria da qualidade e quantidade de água, sinalizando a EA como gestão ambiental e como resolução de problemas ambientais, o que, segundo Amaral (2003), aponta para uma visão utilitarista e antropocêntrica, em que a ciência e a tecnologia estão a serviço da resolução dos problemas.

Esse documento também traz uma visão conservadora de EA, no qual fica explícito o entendimento da EA como forma de mudanças do comportamento humano que, segundo Brügger (1994), essa visão configura um adestramento ambiental. Nessa concepção de EA, há um teor instrumental caracterizado pela mudança de

\footnotetext{
11 Primeira Política de EA refere-se a Política de Educação Ambiental dos Comitês PCJ aprovada em 2004.

12 Política Atual de EA refere-se a uma atualização da primeira política, sendo aprovada no ano de 2015.
} 
comportamento, sendo desprovida de reflexões críticas, buscando o desenvolvimento apenas de posturas e atitudes corretas, sem a preocupação com os pressupostos sociais, políticos e econômicos.

A Deliberação sobre aprovação de projetos de EA no âmbito do licenciamento ambiental foi aprovada em agosto de 2014, momento em que a CT-EA estava atualizando sua Política de EA. Dessa forma, consideramos haver uma certa incoerência teórica e prática, onde a Política Atual de EA tem como característica um viés crítico enquanto que essa deliberação enxerga a EA como mitigadora dos problemas ambientais, demonstrando um viés pragmático.

Pela análise das reuniões e oficinas, as reuniões aconteciam de forma mais burocrática com diversas demandas de trabalho e por mais que a coordenação tentasse implementar um processo participativo, poucas pessoas participavam. Nas oficinas o processo participativo era maior e geralmente tinha um grupo menor de pessoas e mais interessadas nos assuntos abordados. Percebemos durante as oficinas observadas que os participantes utilizavam-se do senso comum ao sugerir ideias para a construção de materiais educomunicativos, ressaltando medidas pragmáticas (como economia de água, por exemplo), sugerindo uma culpabilização do indivíduo.

Por mais relevante que seja a etapa inicial do educar, como o plano da sensibilização, do reconhecimento do ambiente, da ação particular no universo e de ações comportamentais individuais, essas não bastam como ações válidas e suficientes para a transformação da sociedade. É preciso articular o cotidiano com a dimensão macrossocial com uma atuação política que gere transformações individuais e coletivas, ao mesmo tempo, e a partir disso a universalização das experiências locais bemsucedidas (LOUREIRO, 2012).

Em síntese, os registros das reuniões e oficinas demonstraram que não há uma só concepção de EA e sim variadas concepções que se misturam, indicando que não há uma compreensão e clareza dos participantes e da coordenação sobre qual concepção de EA a CT-EA deve sustentar suas práticas.

Ao analisarmos as entrevistas, em suma, na entrevista da coordenadora da CTEA, percebemos que ela tem uma visão crítica da EA, porém enquanto coordenadora tem uma posição clara na tomada de decisão da Câmara, com algumas posturas 
hierarquizadas, apesar de sempre tentar praticar processos participativos e de construção coletiva. Na entrevista com a coordenadora adjunta, ela sinaliza que sua concepção de EA é crítica onde ela não se coloca numa posição hierárquica com os demais membros da CT-EA, dando ênfase aos processos educativos e participativos.

\section{Coerência elou Incoerência na(s) Concepção(ões) de EA da CT-EA}

Como forma de verificar as coerências e/ou incoerências da(s) concepção(ões) de EA presentes nos documentos, nas reuniões e nas entrevistas, realizamos uma análise comparativa entre os mesmos.

A deliberação de criação da CT-EA coloca que as Atas devem conter as discussões e decisões referentes às reuniões. Porém, as Atas das reuniões observadas não apresentam quaisquer discussões acontecidas durante as reuniões. Trazem apenas o assunto discutido e qual foi a decisão e/ou encaminhamentos sobre o mesmo. Dessa forma, há uma incoerência entre o documento e a prática, e a ausência das discussões limitam o acompanhamento documental das reuniões da CT-EA.

$\mathrm{Na}$ deliberação que aprova a CT-EA, em suas considerações é ressaltada a importância da EA como ferramenta para envolver a população com programas de uso racional da água e recursos naturais. Mesmo com a Primeira Política de EA, onde observa forte atuação em projetos de EA dentro dos comitês PCJ, e com a elaboração e aprovação da Política Atual de EA, existem muitos indícios que a CT-EA, em 12 anos de atuação nas bacias hidrográficas, ainda não foi reconhecida por outras instâncias dos Comitês PCJ como tendo uma postura crítica, reflexiva e emancipadora, realçada durante as entrevistas. Logo, entendemos esse distanciamento entre proposição, práticas e resultados uma incoerência entre os documentos, entre os documentos e as entrevistas e entre os documentos e as práticas da CT-EA dentro dos Comitês PCJ.

As Políticas de EA dos Comitês PCJ indicam o anseio em ter uma "construção coletiva e contínua do conhecimento utilizando metodologias participativas que valorizam os conhecimentos e experiências de todos os participantes". Durante as reuniões percebemos pouca participação e interação entre os membros da CT-EA, principalmente durante a reformulação da Política de EA dos Comitês PCJ, onde muitas pessoas não opinavam por falta de conhecimento dos assuntos. Em outros momentos a 
coordenação sempre sugeria maior participação dos membros, porém poucas pessoas se manifestavam.

Outra incoerência encontrada foi a divergência entre a concepção de EA presente na Política Atual de EA e a visão da deliberação que aprova projetos de EA no âmbito do licenciamento ambiental. Nessa deliberação é apresentada uma EA Pragmática enquanto que na Política Atual de EA é adotada uma EA Crítica. Ambos os documentos foram elaborados e aprovados por uma mesma coordenação, por isso considero uma incoerência substancial entre os documentos.

Dentro da CT-EA não há uma só concepção de EA, elas se misturam, ou melhor, nas práticas pode-se depreender variadas e distintas concepções, indicando que não há uma compreensão e/ou clareza dos participantes e da coordenação sobre qual concepção a CT-EA deve se sustentar. Nas Políticas de EA dos Comitês PCJ, em especial na Atual, denota-se a perspectiva de EA Crítica, com viés multidimensional de ambiente e de transformação da realidade além de propor uma participação de forma horizontal; essa mesma concepção é depreendida das entrevistas. Nas práticas (reuniões e oficinas) não há uma só concepção praticada, mas diversas. Consequentemente, as reuniões e oficinas não acompanham os princípios e fundamentos da Política Atual de EA ocorrendo uma incoerência entre os documentos, as práticas e as entrevistas.

Assim, no conjunto dos elementos observados, observa-se uma predominância da incoerência entre os mesmos, em que, entre outros aspectos, a EA crítica prevalece no plano das intenções e a EA pragmática no plano das ações.

\section{CONSIDERAÇÕES FINAIS}

Como contribuições da pesquisa, apontamos o desvelar das concepções de EA da CT-EA dos Comitês PCJ, entendendo que o contexto da CT-EA é constituído de pessoas com diversos olhares, vivências e expectativas sobre o campo da EA e que essa diversidade acaba por influenciar na multiplicidade de concepções de EA encontradas nas práticas da câmara, contribuindo também para entendermos que nem sempre a política e a coordenação orientam suas práticas. 
Importante ressaltar também que existe uma influência política de outras instâncias dos Comitês PCJ sobre as práticas da CT-EA, sendo essa câmara técnica parte integrante de uma estrutura política maior. Dessa forma, pelas análises das Políticas de EA, são colocadas como sendo EA Crítica, porém não são críticas o suficiente para questionar a estrutura ou as formas de trabalho dos Comitês PCJ a fim de colocar-se como parte integrante, participativa e fundamental dentro das ações e discussões dos Comitês PCJ.

Também contribui para a compreensão de que fóruns e espaços de discussão e de tomada de decisão fazem parte de uma estrutura política dependente de diversos outros atores sociais e instâncias e que muitas vezes sofrem influências em suas decisões e posturas.

\section{REFERÊNCIAS}

ABERS, Rebeca; JORGE, Karina D. Descentralização da gestão da água: por que os comitês de bacia estão sendo criados? Ambiente \& Sociedade, v. VIII, $\mathrm{n}^{\mathrm{o}}$ 2, p.1-26, 2005.

ABERS, Rebeca N.; FORMIGA-JOHNSSON, Rosa M; FRANK, Beate; KECK, Margaret E.; LEMOS, Maria C. Inclusão, Deliberação e Controle: três dimensões de democracia nos comitês e consórcios de bacias hidrográficas do Brasil.Ambiente \& Sociedade, Campinas, v. XII, n. 1, p. 115-132, 2009.

ALVES-MAZOTTI, Alda J; GEWANDSZNAJDER, Fernando. O método nas Ciências Naturais e Sociais: pesquisa quantitativa e qualitativa. 2. Ed. São Paulo: Pioneira Thomson Learning, 2001.

AMARAL, Ivan A. do. A educação Ambiental e o Currículo Escolar.Contestado e Educação - Revista Virtual, n. 6, n.p., out/dez.2003.

A educação ambiental nos currículos escolares.Campinas: Faculdade de Educação, Unicamp, n.p., 2006. [Trabalho não publicado].

BAGNOLO, Carolina M. Empresariado e ambiente: algumas considerações sobre a Educação Ambiental no espaço escolar. Ciência \& Educação, Bauru, v.16, n. 2, p. 401-413, 2010.

BARBI, Fabiana. Capital social e ação coletiva na gestão das bacias dos rios Piracicaba, Capivari e Jundiaí: os desafios da gestão compartilhada do Sistema Cantareira - SP. Dissertação de Mestrado - Faculdade de Educação, Universidade de São Paulo, 2007, 158 p.

BRÜGGER, Paula. Educação ou adestramento ambiental. Coleção teses. Santa Catarina: Letras contemporâneas, 1994.

CARVALHO, Isabel C. de M. A invenção ecológica: narrativas e trajetórias da educação ambiental no Brasil. 2a. ed. Porto Alegre: Editora da UFRGS, 2002.

FREIRE, Paulo. Pedagogia da esperança: um reencontro com a pedagogia do oprimido. São Paulo: Paz e Terra, 1992.

GUIMARÃES, Mauro. A Formação de agentes ambientais. Campinas: Papirus, 2000. 
LAHÓZ, Francisco C.C. Meio ambiente e cultura no século 21. Apresentação de mesa no IV Diálogo Interbacias de Educação Ambiental e, Recursos Hídricos. Avaré, São Paulo, 2006.

LAYRARGUES, Phillipe P.; LIMA, Gustavo F. C. As macrotendências políticopedagógicas da educação ambiental brasileira.Ambiente \& Sociedade, Campinas, v. 17, n. 1, p. 23-40, 2014.

LIMA, Gustavo F. da C. Educação Ambiental no Brasil: informações, identidades e desafios. Campinas: Papirus, 2011.

LOUREIRO, Carlos F. B. Trajetória e fundamentos da Educação Ambiental. 4 ed. São Paulo: Cortez, 2012.

MARCONI, Marina A. de; LAKATOS, Eva M. Técnicas de pesquisa: planejamento e execução de pesquisas, amostragens e técnicas de pesquisas e elaboração, análise e interpretação de dados. São Paulo: Atlas, 2011.

PAULA, Gabriela O. de. A Água: percepções e compromisso Estudo de caso na Região Metropolitana de Campinas. Tese de Doutorado - Instituto de Geociências, Universidade Estadual de Campinas/UNICAMP, Campinas, 2002, p. 281.

REIGOTA, Marcos. Educação Ambiental: fragmentos de sua história In: NOAL, Fernando O.; REIGOTA, Marcos; BARCELOS, Valdo H. de L. (Orgs). Tendências da Educação Ambiental brasileira. 2 ed.Santa Cruz do Sul: EDUNISC, 2000, p. 13 - 27.

RINK, Juliana. Ambientalização curricular na Educação Superior: tendências reveladas pela pesquisa acadêmica brasileira (1987-2009). Tese de Doutorado, Faculdade de Educação - Universidade Estadual de Campinas/Unicamp, SP, 2014.

SAUVÉ, Lucie. Uma cartografia das Correntes em educação ambiental In: M. SATO; I. C. M. CARVALHO (org.). Educação Ambiental. Porto Alegre: Artmed, 2005, p. $17-45$.

SÃO PAULO. Deliberação Conjunta dos Comitês PCJ n002/03, de 22/05/2003. Aprova a criação da Câmara Técnica de Educação Ambiental dos Comitês das Bacias Hidrográficas dos Rios Piracicaba, Capivari e Jundiaí - CBH-PCJ e PCJ Federal. 3 p., 2003. Disponível em: <http://www.comitespcj.org.br/>. Acesso em: 10 abr. 2014.

SETTI, Arnaldo A.; LIMA, Jorge E. F. W.; CHAVES, Adriana G. M.; PEREIRA, Isabella C. Introdução ao Gerenciamento de Recursos Hídricos. Brasília: Agência Nacional de Energia Elétrica, Agência acional de Águas, 3 ed.2001, 328p.

SORRENTINO, Marcos. Educação Ambiental e Universidade: um estudo de caso. Tese de Doutorado. São Paulo: Universidade de São Paulo, 1995.

.Vinte anos de Tbilisi, cinco da Rio-92: A Educação

Ambiental no Brasil. Debates Socioambientais. CEDEC, São Paulo, ano II, n. 7, p.35, jun./set 1997.

SZYMANSKI, Heloísa (org.); ALMEIDA, Laurinda R. de; PRANDINI, Regina C. A. R. A Entrevista na pesquisa em educação: a prática reflexiva. Brasília: Líber Livro, 2008 (Série Pesquisa em Educação, v. 4). 